\title{
Anabases
}

ANABASES Traditions et réceptions de l'Antiquité

14 | 2011

Varia

\section{André LARONDE et Jean LECLANT (éd.), Journée d'hommage à François Chamoux}

\section{Geneviève Hoffmann}

\section{OpenEdition}

\section{Journals}

Édition électronique

URL : http://journals.openedition.org/anabases/2411

DOI : 10.4000/anabases. 2411

ISSN : 2256-9421

\section{Éditeur}

E.R.A.S.M.E.

\section{Édition imprimée}

Date de publication : 1 octobre 2011

Pagination : 277-279

ISSN : 1774-4296

\section{Référence électronique}

Geneviève Hoffmann, «André LARONDE et Jean LECLANT (éd.), Journée d'hommage à François Chamoux », Anabases [En ligne], 14 | 2011, mis en ligne le 01 octobre 2011, consulté le 21 septembre 2020. URL: http://journals.openedition.org/anabases/2411 ; DOI : https://doi.org/10.4000/anabases.2411

Ce document a été généré automatiquement le 21 septembre 2020.

(c) Anabases 


\title{
André LARONDE et Jean LECLANT (éd.), Journée d'hommage à François Chamoux
}

\author{
Geneviève Hoffmann
}

\section{RÉFÉRENCE}

André LARONDE et Jean LECLANT (éd.), Journée d'hommage à François Chamoux, Paris, Académie des inscriptions et belles-lettres, 2010, $130 \mathrm{p}$.

30 euros / ISBN : 978-2-87754-242-5.

1 Le 11 janvier 2008, l'Académie des inscriptions et belles-lettres a honoré la mémoire de l'un de ses membres, François Chamoux (1915-2007), en organisant une journée d'étude publiée sous la forme d'un livre élégant, dont la couverture est illustrée par la photographie du temple d'Apollon de Cyrène (cliché A. Laronde, 1977).

2 Le plan de l'ouvrage suit fidèlement le programme de la journée. Dans son allocution d'accueil, Jean Leclant retrace brièvement la carrière de François Chamoux (FC); Adrien Fauve évoque son grand-père à «la sensibilité littéraire saisissante » (p. 4), et Alain Plantey loue son rôle dans le sauvetage du musée Jacquemart-André. Si FC a suivi la voie royale d'une carrière qui le conduisit de l'École normale supérieure à la Sorbonne, où il occupa la chaire de littérature et civilisation grecques de 1960 à 1983, il joua un rôle pionnier en Libye comme fondateur en 1976 de la Mission Archéologique Française qu'il dirigea jusqu'en 1981, avant de laisser sa place à André Laronde. Sa thèse, Cyrène sous la monarchie des Battiades, publiée en 1953 (et non en 1955, p. 2), donna, on le sait, une impulsion décisive à l'hellénisme cyrénéen. Ce portrait, complété par une photo de $\mathrm{FC}$ en habit d'Académicien prise en 2005 dans la Bibliothèque de l'Institut, impose l'image d'un notable des lettres et d'un humaniste, ainsi que d'un citoyen dévoué au service public. FC était aussi un enseignant passionné et exigeant 
comme en témoignent les cinq auteurs des communications qui ont donné à cette journée sa dimension scientifique.

3 Pour Catherine Dobias-Lalou (p.7-20), FC, épigraphiste talentueux, a proposé des relectures d'inscriptions qui font désormais autorité. Il eut surtout le mérite de souligner l'importance de l'épigramme grecque pour la connaissance des sociétés, alors que son étude était négligée par les philologues. La liste des articles consacrés par FC à ce genre littéraire en appendice, suivie par une page inédite sur ce même sujet, témoigne en effet de cet intérêt constant. Paul Goukowski rappelle les étapes de l'entreprise ambitieuse que fut l'édition française de la Bibliothèque Historique de Diodore de Sicile, que FC entama dès 1960, après son élection à la Sorbonne (p. 25-36). Dans l'introduction du Livre I (1993), FC a développé sa conception d'une œuvre longtemps méprisée et dont les historiens reconnaissent aujourd'hui la valeur documentaire. FC sut également voir en Pausanias un observateur attentif aux faits comme aux mythes. C'est ce regard qu'a adopté Madeleine Jost dans son étude sur "Pausanias et la religion grecque» (p.37-46). Elle démontre une fois de plus que la Périégèse n'est pas seulement indispensable à l'archéologue, mais qu'elle donne également des informations essentielles à l'historien, encore faut-il savoir comprendre les silences de son auteur et cerner « cette curiosité maîtrisée » qui le caractérise. Dans un style alerte, Denis Knoepfler (DK) invite le lecteur à une promenade archéologique du vallon des Muses héliconiades à l'Éros thespien de Praxitèle (p. 47-67), promenade d'autant plus plaisante qu'elle est jalonnée de cartes et de reproductions des œuvres citées. Sa contribution rend vivante la présence de FC avec qui il a correspondu pendant près de 40 ans, tout en soulignant la pertinence de sa méthode et la justesse de certaines de ses interprétations. Il rappelle à juste titre que la statue appelée « Éphèbe de Marathon » (p. 55, figure 3) est bien un Hermès à la tortue. Le catalogue du Louvre le présente comme un vainqueur aux concours, alors que l'interprétation donnée par FC date de 1959 et a été rappelée en 1998 et 2000. DK reconnaît que ses propres lectures ont parfois suscité la perplexité de FC - de la chronique des heurs et malheurs de l'Éros thespien à la restitution du nom du sculpteur Sthennis d'Olynthe dans la Périégèse (IX, $30,1)$ «en lieu et place de ce beau monstre Olympiosthénès »! Jean-Jacques Maffre rappelle l'intérêt de FC pour l'iconographie des vases, de la coupe laconienne d'Arcésilas, conservée au Cabinet des Médailles, aux vases attiques à figures rouges. Pour cet hommage il retient des pièces venant de trois lieux chers à son prédécesseur à la Sorbonne : Thasos, Athènes et la Cyrénaïque (p. 69-94). En suivant la voie tracée par "le maître ", il propose des interprétations éclairées par des parallèles avec d'autres domaines de l'art antique. Après avoir tiré brièvement les conclusions de la matinée (p. 95-97), André Laronde propose une relecture de la thèse de FC sur Cyrène (p. 99-104). Par le choix de quelques thèmes, il démontre que les apports les plus récents de la recherche n'ont pas rendu cette œuvre obsolète. Mario Luni clôt cet hommage par l'exposé des fouilles conduites par la Mission archéologique italienne de l'université d'Urbino sur le Dioskourion de Battos, découvert à Cyrène dans le quartier de l'agora (p. 105-120). Présentation suivie par l'analyse de la dédicace aux Dioscures, gravée sur un calice, dédicace qui serait l'inscription la plus archaïque de Cyrène connue à ce jour. Silva M. Marengo (p. 120-129), responsable de cette étude ainsi que de celle des graffiti de Cyrène, n'a pas son nom cité dans la liste des participants ainsi que dans la table des matières. l'image du dynamisme scientifique et de l'ouverture d'esprit de FC, philologue, 
archéologue, historien et fin connaisseur de l'art grec. Les filles de la Mémoire sauront accueillir François Chamoux "comme un serviteur parmi les plus fervents, les plus doués et les plus courageux » (p. 67) sur cette terre de Libye âprement disputée.

\section{AUTEURS}

\section{GENEVIĖVE HOFFMANN}

Université de Picardie Jules Verne

Genevieve.hoffmann@wanadoo.fr 